\title{
Development of a dynamic biogeographic information system for the Gulf of Maine
}

\author{
V.M. Tsuntos and D.A. Kiefer \\ Unizersity of Southern California - Los Angeles, California USA
}

\begin{abstract}
Central to the development of an inventory of marine life and improved conceptual understanding of the mechanisms that dynamically shape species distribution patterns needed for renewable resource management is the implementation of strategies aimed at enhancing assimilation and access to existing biogeographical information. Using the internet as a medium and EASy (Environmental Analysis System), an advanced oceanographic geographic information system (GIS) tool, the Gulf of Maine Biogeographic Information System (GMBIS) project will provide a framework for the integration, visualization, analysis and dissemination of diverse types of biogeographical and oceanographic information. End-to-end viability of this approach is demonstrated in the context of a pilot application for the Gulf of Maine, a well-studied ecosystem for which extensive scientific data exist but one that historically has been subject to large-scale perturbation due to overharvesting. Databases at the core of the information system will include those of the Bedford Institution of Oceanography and Atlantic Reference Center, which are the product of multidisciplinary research efforts over the last 30 years in the Gulf of Maine. The development of GMBIS may serve not only as a model for the global Ocean Biogeographic Information System, but it may also will provide a powerful tool to meet the new international and Canadian national demands for integrated and ecologically responsible management of marine resources.
\end{abstract}

\section{Introduction}

Human activities now rival natural processes in terms of their impacts on marine ecosystems. An amelioration of this condition will most likely result from improved understanding of the range of processes that interact to shape these systems. The situation is exemplified by the status of marine fisheries, which despite management efforts, are at a critical juncture due to chronic problems of overcapitalization, overutilization and resource depletion (Sissenwine \& Rosenberg, 1993;
Rosenberg et al., 1993). Here single species approaches have historically provided the basis for scientific assessment and management of harvested marine populations. Achieving sustainable use of these resources in the future, however, is likely to require a paradigm shift in which both multi-species and ecosystem perspectives are considered (Murawski, 1991; ICES, 1999; National Research Council, 1999).

Central to an improved understanding of marine ecosystem function is the study and cataloguing of species diversity and species distribution patterns (May, 1990). The development of the Ocean Biogeographical Information System (OBIS) as proposed by the Organisation for Economic Co-operation and Development is an important step towards this end. However, the development of such an inventory of marine life poses significant technical and conceptual challenges because a global assessment of marine life requires a description of the spatial dynamics and temporal evolution of biomass distributions between taxa and trophic groups (Bradley, 1999; Alldredge et al., 1999). The Sloan Foundation/NOPP "Census of Marine Life" initiative addresses this and aims to make it more tractable by establishing a series of eight pilot projects that focus on different technical facets of the problem (Malakoff, 2000). These range from methods for the identification of species to approaches for integrating and improving access to biogeographical information.

One such pilot application is the GMBIS. The basic objective of GMBIS is to develop a methodological framework for enhancing access to and assimilation of existing data relevant in marine biogeographical and ecological studies. GMBIS will assemble a prototype information system for the integration, visualization, analysis and dissemination of multivariate biogeographical and oceanographic information, using the Internet as a medium and capitalizing upon database technologies and tools such as GIS for the modeling of spatially referenced data. The system will provide a tool for better understanding regulation in fish populations in terms of 
bio-physical processes operative over multiple spatiotemporal scales (Shepherd \& Cushing, 1990; Kareiva, 1990; Powell, 1989; Steele, 1989; Levin, 1995) and in terms of underlying interspecific, habitat and fisheries interactions (Murawski, 1991; Langton \& Auster, 1999). It will also support studies of biogeography, proving particularly useful for those where patterns of species diversity are viewed as dynamic and the product of an interplay between population dynamics and evolutionary processes (Travis, 1990; Rapoport, 1994).

End-to-end viability of the GMBIS information system will be demonstrated in the context of a pilot application for the Gulf of Maine. The Gulf of Maine is ideally suited for testing such an approach. This area marks a major biographic discontinuity between north and south temperate species (Mahon et. al., 1998) making it a natural focus for the development of a biogeographic information system. Secondly, the Gulf is a well-studied system, and one for which extensive, multidisciplinary scientific data exist. Databases maintained by the collaborating Bedford Institution of Oceanography and Atlantic Reference Center will form the core of the GMBIS information system. These datasets have fueled numerous studies in physical oceanography (Loder et al., 1993; Werner et al., 1997), population genetics (Purcell et al., 1996; Ruzzante et al., 1999) and fish ecology (eg. Townsend, 1992; Wigley, 1992). This data archive is particularly important because it documents the effects of large-scale ecosystem disturbance due to harvesting (Fogarty and Murawski, 1998) and provides the empirical basis for the management and recovery of fisheries resources within this ecologically sensitive area.

Development of GMBIS will provide a decision support tool facilitating integrated approaches to fisheries management in the Gulf of Maine. It is thus a timely response to national and international directives such as the 1997 Canadian Oceans Act and the United Nations Food and Agriculture Organization (FAO) Code of Conduct for Responsible Fisheries, and new directions in groundfish fisheries management being adopted in the region (Sinclair et al., 1999). Ultimately, the utility of the Gulf of Maine Biogeographic Information System may be to serve as a model for OBIS and provide a generic framework for development of biogeographic systems in other regions.

\section{Information System Design and Data Flow}

GMBIS is composed of a hierarchy of three broad categories of components (Figure 1). Information flows from the data sources to the end-user via a series of data integration processes and visualization interfaces. GMBIS facilitates remote access to multiple interfaces simultaneously, thus promoting parallel access to a range of information of relevance to biogeographical studies.

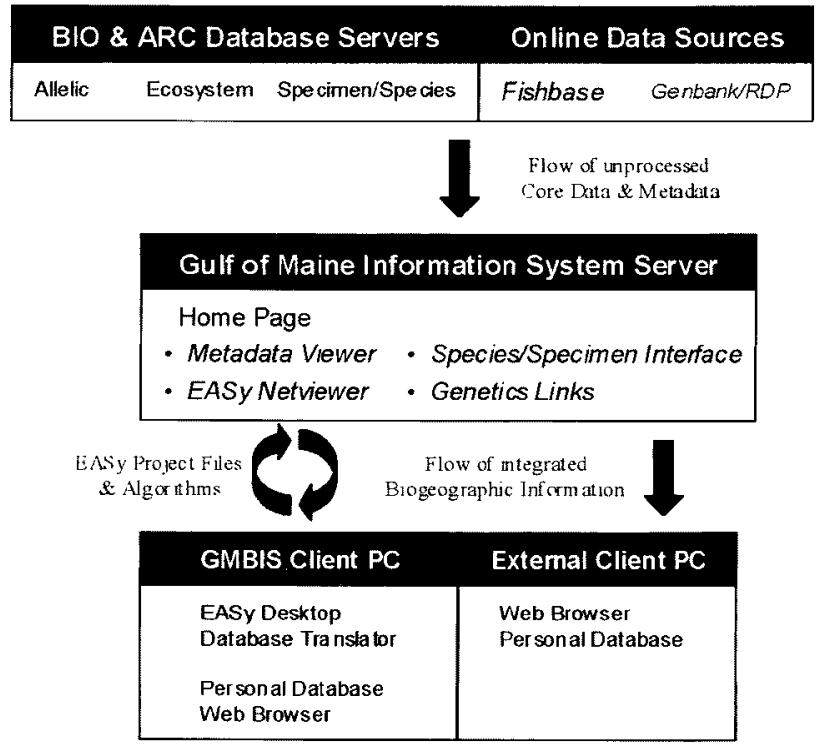

Figure 1. Flow of data and basic design of the Gulf of Maine Bingeographic Information System.

At the highest level are the databases that hold both core biogeographical data and the associated metadata that describe them. Three broad classes of databases are identified. The Ecosystem database, maintained on the Bedford Institute of Oceanography (BIO) server, will provide an extensive series of spatially referenced data on environmental conditions, species distribution, and resource exploitation for the Gulf of Maine (Table 1). Established by the Canadian Department of Fisheries and Oceans (MFD) to improve the study and management of transboundary fish stocks within the Northern Atlantic, the resultant data archive represents one of the best scientific records on marine ecological dynamics and biodiversity available for the Gulf of Maine.

The Specimen/Species database will contain information on the taxonomy, morphology, and basic ecology of species that will derive from two sources. The Atlantic Reference Center (ARC) is the designated specimen repository for the Department of Fisheries and Oceans, Canada Maritimes Region. It maintains major holdings and associated data for the Gulf of Maine and Northwestern Atlantic that are of immense research and educational value due to their wide phylogenetic, geographic, and historic coverage. The ARC server will distribute to GMBIS natural history information and specialized information on its specimen collections for the pilot project area. Linkage to Fishbase will provide complementary information for a 
broader geographical region. It will also serve to illustrate the potential for using certified on-line sources of biogeographical information that is becoming increasingly available. Developed by the International Center for Living Aquatic Resources Management (ICLARM) in collaboration with the FAO, FishBase is a searchable catalogue, containing illustrations and descriptive textual information on the natural history and exploitation/conservation status of the world's fish species. The archive currently contains records for 23,000 species, including those found within the Gulf of Maine.

The final database category includes information pertaining to both the genetic structure of populations and the detailed genomic character of species. The BIO server will host data on the allelic variability of harvested marine populations within the Gulf of Maine (Table 1). Complementary nucleic sequence information for species identification and phylogenetic analysis will be available via links to established on-line databases, such as GenBank and the Ribosomal Database Project (RDP). GenBank is the National Institute of Health (NIH) genetic sequence archive, containing an annotated collection of all publicly available DNA. RDP provides complementary ribosome related data services to the scientific community, including online data analysis, rRNA derived phylogenetic trees, and aligned and annotated rRNA sequences.

The second level of GMBIS comprises the software methods and interfaces for the remote interrogation, coupling, visualization, and analysis of multivariate biogeographical and oceanographic information from these data sources. User access to these tools is via the GMBIS Internet home page. The Metadata Viewer provides a standard visual interface for the querying

\begin{tabular}{|c|c|c|c|}
\hline \multirow[b]{2}{*}{ Database } & \multicolumn{3}{|c|}{$\begin{array}{l}\text { TABLE I } \\
\text { Summary of electronically archived data maintained by } \\
\text { the Bedford Institute of Oceanography that will be accessed by GMBIS. }\end{array}$} \\
\hline & Survey Type & Period \& Frequency & Data Description \\
\hline Groundfish & $\begin{array}{l}\text { Stratified random } \\
\text { Research Trawl }\end{array}$ & 1970-1999; 1-3/year & $\begin{array}{l}\text { - } 300 \text { vertebrate and invertebrate species } \\
\text { - georeferenced catches (total numbers and weight) } \\
\text { - size-frequency distributions } \\
\text { - subsample length, weight, age, sex, maturity } \\
\text { - Temperature-salinity profiles or surface/bottom values }\end{array}$ \\
\hline Larval & $\begin{array}{l}\text { SSIP/FEP egg and } \\
\text { larval surveys } \\
\text { Herring larval } \\
\text { surveys }\end{array}$ & $\begin{array}{l}1976-1999 \\
1972-1999\end{array}$ & $\begin{array}{l}\text { - georeferenced egg/larval abundances } \\
\text { - } 487 \text { species } \\
\text { - georeferenced herring larval abundances }\end{array}$ \\
\hline Fisheries & $\begin{array}{l}\text { ICNAF/NAFO } \\
\text { Canadian National } \\
\text { Catch Statistics } \\
\text { Fishing Vessel } \\
\text { Logbooks } \\
\text { Fishing Vessel Port } \\
\text { Landings } \\
\text { At-Sea Observer } \\
\text { records }\end{array}$ & $\begin{array}{l}\text { 1969-1999; monthly } \\
\text { 1960-1999; monthly } \\
1991-1999 \\
1947-1999 \\
1977-1999\end{array}$ & $\begin{array}{l}\text { - catch statistics for } 151 \text { species } \\
\text { - catch statistics for } 158 \text { species } \\
\text { - geo-referenced catch records for } 158 \text { species } \\
\text { - biological length/age samples for } 37 \text { species }\end{array}$ \\
\hline Genetic & Population Genetics & $1993-1999$ & $\begin{array}{l}\text { - cDNA and microsatellite gene probe data } \\
\text { - commercially harvested species NW Atlantic (scallop, } \\
\text { lobster, cod, haddock, herring) }\end{array}$ \\
\hline Climate & Hydrographic & $1920-1999$ & - temperature/salinity profiles \\
\hline SST & $\begin{array}{l}\text { Remote Sensing } \\
\text { Data }\end{array}$ & & $\begin{array}{l}\text { - JPL } 18 \text { km MCSST (sea surface temperature) } \\
\text { - SeaWifs chlorophyll }\end{array}$ \\
\hline ODI & $\begin{array}{l}\text { Ocean Data } \\
\text { Inventory }\end{array}$ & $1965-1999$ & - current meter and thermograph time series \\
\hline BIOCHEM & $\begin{array}{l}\text { National Marine } \\
\text { Biological and } \\
\text { Chemical Database }\end{array}$ & $\begin{array}{l}1970-1999 \\
1960-1999\end{array}$ & $\begin{array}{l}\text { - BIO nutrient data } \\
\text { - approximately } 100 \text { chemical parameters } \\
\text { - NW Atlantic Zooplankton samples } \\
\text { - continuous Plankton Recorder data (lines E and Z) }\end{array}$ \\
\hline
\end{tabular}




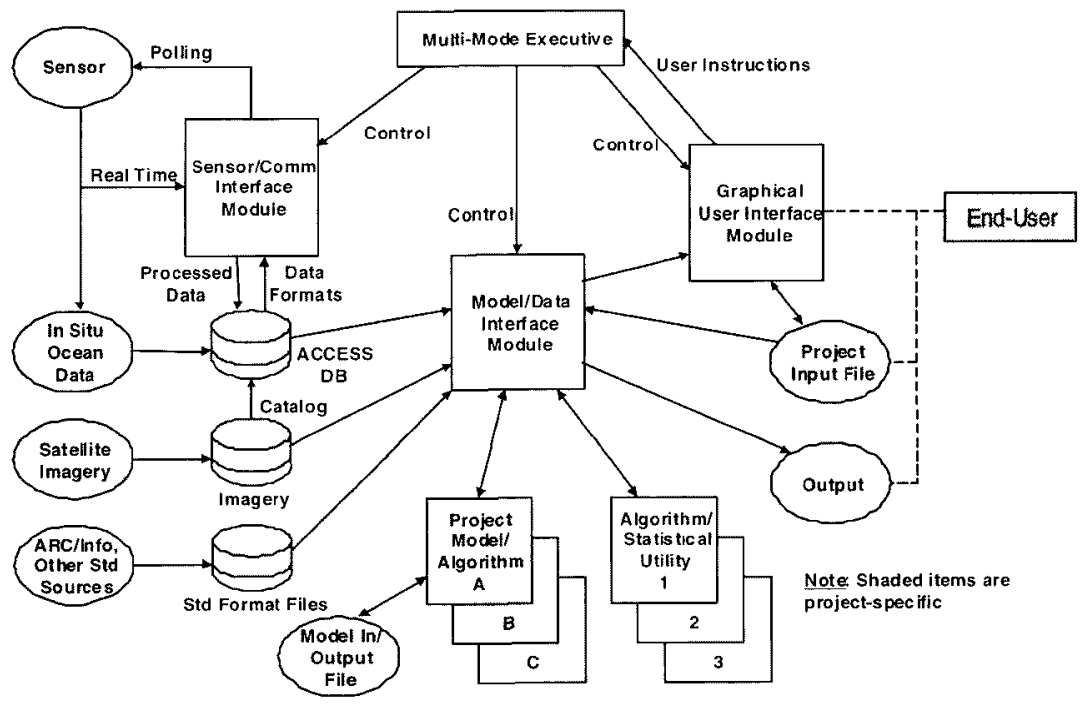

Figure 2. Modular architecture underlies the GIS software system.

\section{Advanced GIS Capability}

The incorporation of a GIS component within GMBIS follows from an understanding of the importance of spatial processes in influencing marine population and ecosystem dynamics (Kareiva, 1990; Wright \& Bartlett, 2000). EASy is an advanced geographical information system designed for the storage, dissemination integration, analysis and dynamic display, of spatially referenced series of diverse oceanographic data. EASy is a PC-based GIS package, developed by Systems Science Applications, Redondo Beach, California (http://www.systemscienceapp.com/). It has been used in a range of national and international oceanographic projects, including the storage and mapping of bio-optical parameters in the Atlantic Ocean and Mediterranean Sea, examining the effect

and cross-referencing of available metadata. The value of the Metadata Viewer for GMBIS end-users is that it permits identification of relevant biogeographical and environmental data across diverse sources. It provides a means of homing in on subsets of thematically related information and data that are coincident in terms of their spatial and temporal extent or share other userdefined criteria. The Specimen/Species interface provides end-users with an electronic form for querying the archives of ARC and the more generic FishBase site for information on natural history or specimen collections. In a similar manner, the Genetics Interface will facilitate the querying and exporting data from the BIO population genetics database and will provide links to established online gene sequence data resources. The GMBIS server will run a new Web-based, oceanographic GIS, for integrated ocean management. Netviewer EASy. EASy is the principal data integration, viewing and analysis software of GMBIS, and its Netviewer component will permit broad access to interactively defined, value-added graphical data products across the Internet.

GMBIS distinguishes between two types of information system users. External clients, users not directly involved in system development work, will access GMBIS server interfaces, query databases, operate Netviewer and download integrated data products as text, maps and plots, via their internet browser. GMBIS clients will have the additional GIS functionality and the greater assortment of analytical tools afforded by the desktop version of EASy, permitting development of EASy project files and algorithms that will then be incorporated into the Netviewer version for use on the Web. of wind-induced upwelling for fisheries recruitment dynamics in the Mediterranean, and the modeling of effluent dispersion from storm drains in Santa Monica Bay.

The software has been custom designed with the particularities of oceanographic applications, the needs of marine research and educational communities, and pathways for information exchange in mind. It facilitates the interfacing of multivariate oceanographic data, including satellite imagery, with statistical algorithms and mechanistic models. It graphically renders dynamically in time, within their proper geospatial context, both field and remotely sensed data and model outputs as diverse types of plots, including vector, contour, and false color image plots. Vertical structure of data, critical in oceanographic applications, is depicted as vertical contours for user defined transects or depth profiles at selected point locations. Time series of measurements, and dependencies between data at individual stations can also be visualized interactively as $X-$ $Y$ plots. The GIS facilitates the exploration of patterns in data over multiple space and time scales, and permits resolution of inherent mismatches in the spatial and temporal sampling frequency of underlying datasets.

EASy's architecture is modular in structure (Figure 2), thereby making it relatively simple to extend the functionality of the software by linking additional database libraries, data analysis tools and other services. One can import satellite imagery in various formats, link to SQL relational databases and external ASCII data files, and interface with mathematical models and statistical algorithms. Project algorithm modules contain a wide range of models that can be tapped by applications from 
widely used statistical functions and spatial interpolation methods to more specialized bio-optical algorithms for the analysis of remote sensing data. The communications module handles all aspects pertaining to the remote data transfer, from the acquisition of imagery or in-situ data from a remote ftp site to the real time polling of sensors in the field. A "Netviewer" version of the GIS, permits querying, visualization and computation of data real-time over the Internet. The Netviewer thus facilitates broad, platform-independent access to oceanographic data and analysis across the Web simply running standard Internet browsers.

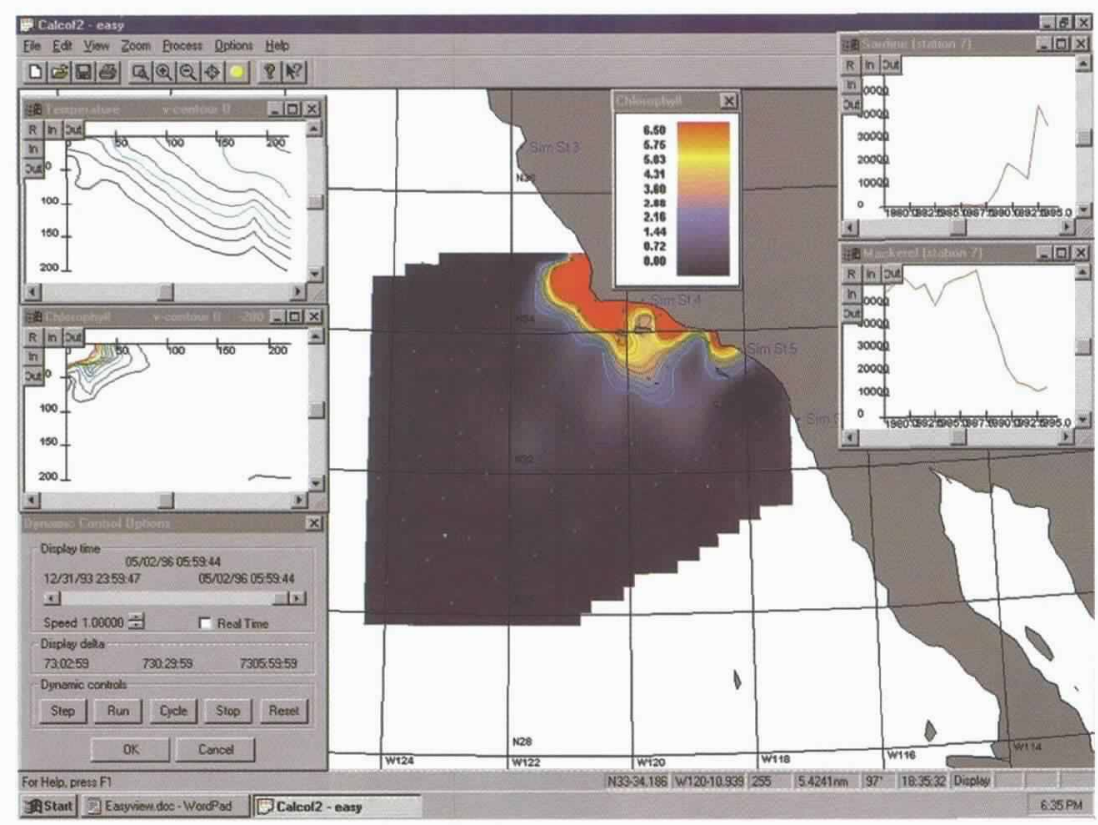

Figure 3. False color image plot of surface chlorophyll concentrations from the CalCOFI EASy project. A large phytoplankton bloom off of Point Conception appears as red in the image, and is associated with coastal upwelling as seen in the temperature and chlorophyll vertical contour plots (upper left). Time series of the mackerel and sardine landings at ports along the coast from 1980 to 1995 are also displayed (Top Right), suggesting that the dynamics of these species are out of phase.

The GIS has been applied to integrate some of the time series of multivariate oceanographic information from the California Co-operative Fisheries Investigation (CalCOFI) program. This dataset comprises 60 years' worth of spatial abundance data for eggs, larvae and adults of approximately 90 fish species. It also includes coincident measurements on the biochemical composition of the water column. EASy with its Netviewer interface is currently on trial with the Southwest Fisheries Center to interactively visualize and distribute selected portions of CalCOFI data and resulting integrated value added data products via the Internet (Figure 3).

\section{Conclusions}

The Gulf of Maine Biogeographic Information System is a pilot project that will assimilate and inte- grate extensive marine ecosystem and fisheries data and natural history information that have been collected by the Bedford Institute of Oceanography and the Atlantic Reference Center. If successful, the project will make this information more accessible to marine scientists and eventually to the public. Although scientific understanding and decisions on the exploitation of marine resources are limited by the fact that the ocean is inadequately monitored and sampled, it may also be argued that the data gathered are often neither readily accessible nor easily integrated with associated information. GMBIS will address the latter two problems: data accessibility and integration.

At least from the perspective of resource management, the timing of the OBIS project is opportune. Under the emerging national and international oceans legal framework for marine resources, there is the need for integrated ocean management. The management plans for ocean industries, such as oil and gas extraction, marine transportation and fisheries, will increasingly be evaluated in relation to broader properties of ecosystems. Criteria and management reference points include the maintenance of ecosystem, genetic and species diversity, the recovery of species at risk of endangerment and maintenance of exploited species, and the maintenance of trophic level balance. GMBIS may be used as a decision support tool for the implementation of the new Canadian ecosystem directives for the ecologically sensitive Gulf of Maine area. The Gulf of Maine Biogeographic Information System may also serve as a prototype for OBIS, providing a technical framework for the development and implementation of biogeographic systems in other regions.

\section{REFERENCES}

Alldredge, L.A., D.L. Bradley, D. Butterworth and J.H. Steele, 1999: Assessing the Global Distribution and Abundance of Marine Life: Summary of a Workshop Sponsored by the Sloan Foundation and the Office of Naval Research, January 13-15, 1998, Monterey, California. Oceanography, 12(3), 41-46.

Bradley, D.L., 1999: Assessing the Global Distribution and Abundance of Marine Organisms. Oceanography, 12(3), 19-20.

Fogarty, M.J. and S.A. Murawski, 1998: Large-scale Disturbance and the Structure of Marine Systems: Fishery Impacts on Georges Bank. Ecological Applications, 6-22.

ICES, 1999: Report of the ICES Advisory Committee on the Marine Environment, 1998. ICES Cooperative Research Report, 233, 94-220. 
Kareiva, P., 1990. Population Dynamics in Spatially Complex Environments: Theory and Data. Phil. Trans. R. Soc. Lond. B., 330, 253-259.

Langton, R.W. and P.J. Auster, 1999: Marine Fishery and Habitat Interactions: To What Extent are Fisheries and Habitat Interdependent? Fisheries, 24(6), 14-21.

Levin, S.A., 1995: The Problem of Pattern and Scale in Ecology. In: Ecological Time Series. T.M. Powell and J.H. Steele, eds., Chapman and Hall, New York, 275326.

Loder, J.W., K.F. Drinkwater, N.S. Oakey and E.P.W. Horne, 1993: Circulation, Hydrographic Structure and Mixing at Tidal Fronts. Phill. Trans. R. Soc. Lond. A, 36, 447-460.

Mahon R., S.K. Brown, K.C.T. Zwanenburg, D.B. Atkinson, K.R. Buja, L. Claflin, G.H. Howell, M.E. Monaco, R.N. O'Boyle and M. Sinclair, 1998: Assemblages of demersal fishes of the east coast of North America. Can. J. Fish. Aquat. Sci., 5S, 1704-1738.

Malakoff, D., 2000: Grants Kick Off Ambitious Count of All Ocean Life. Science, 288, 1575-1576.

May, R.M., 1990: How Many Species? Phil. Trans. R. Soc. Lont. B., 330, 293-304.

Murawski, S.A., 1991: Can we Manage our Multispecies Fisheries? Fisheries, 16(5), 5-13.

National Research Council, 1999: Sustaining Marine Fisheries, Report of Committec on Ecosystem Management for Sustainable Marine Fisheries. Oceans Studies Board, 168pp.

Powell, T.M., 1989: Physical and Biological Scales of Variability in Lakes, Estuaries and the Coastal Ocean. In: Perspectives in Ecological Theory. J. Roughgarden, R.M. May, and S.A. Levin, eds., Princeton University Press, Princeton, 157-176.

Purcell, M.K., I. Kornfield, M. Fogarty and A. Parker, 1996: Interdecadal Heterogeneity in Mitochondrial DNA of Atalntic Haddock (Melogrammus aeglefinnus) from Georges Bank. Molecular Mar. Bio. and Biotechlin., 5(3), 185-192.

Rapoport, E.H., 1994: Remarks on Marine and Continental Biogeography: An Areographical Viewpoint. Phill. Trans. R. Soc. Lond. B., 343, 71-78.

Rosenberg, A.A., M.J. Fogarty, M.P. Sissenwine, J.R. Beddington and J.G. Shepherd, 1993: Achieving
Sustainable Use of Renewable Resources, Science, 262, 828-829.

Ruzzante, D.E., C.T. Taggart, and D. Cook, 1999: A Review of the Evidence for Genetic Structure of Cod (Gadus morhua) Populations in the NW Atlantic and Population Affinities of Larval Cod off Newfoundland and the Gulf of St. Lawrence. Fisheries Research, 103, 79-97.

Shepherd, J.G. and D.H. Cushing, 1990 Regulation in Fish Populations: Myth or Mirage? Phil. Trans. R. Soc. Lond. B., 330, 253-259.

Sinclair M., R.N. O'Boyle, D.L. Burke and F.G. Peacock, 1999: Groundfish management in transition within the Scotia-Fundy area of Canada. ICES J. Mar. Sci., 56(6), 1014-1023.

Sissenwine, M.P. and A.A. Rosenberg, 1993: Marine Fisheries at a Critical Juncture. Fisheries, 18(10), 6-14.

Saarenmaa, H. 1999: A Possible Technical Implementation of the Global Biodiversity Information Facility. European Environment Agency, Technical Reports, Copenhagen.

Steele, J.H., 1989: Scale and Coupling in Ecological Systems. In: Perspectives in Ecological Theory, J. Roughgarden, R.M. May, and S.A. Levin, eds. Princeton University Press, Princeton, 157-176.

Townsend, D.W., 1992: Ecology of Larval Herring in Relation to the Oceanography of the Gulf of Maine. Journal of Plankton Research, 14(4), 467-493.

Travis, J., 1990: The Interplay of Population Dynamics and the Evolutionary Process. Phill. Trans. R. Soc. Lond. B., 330, 253-259.

Werner, F.E., J.A. Quinlan, B.O. Blanton and R.A. Luettich, 1997: The Role of Hydrodynamics in Explaining Variability in Fish Populations. Journal of Sea Research, 131, 195-212.

Wigley, S.E. and F.M. Serchuk, 1992: Spatial and Temporal Distribution of Juvenile Atlantic Cod Gadus morhua in the Georges Bank-Southern New England Region. Fishery Bulletin, 90, 599-606.

Wright, D. and D. Bartlett, 2000: Marine and Coastal Geographic Information Systems. Taylor \& Francis, London, 320pp. 